\title{
Constraints in adoption of composite carp culture in central Brahmaputra valley zone of Assam - a perceptual framework
}

\author{
Pradip C. Bhuyan ${ }^{1 *}$, Chandan Goswami ${ }^{2}$, Bipul Kr. Kakati ${ }^{1}$ and Kaustubh Bhagawati ${ }^{1}$ \\ ${ }^{1}$ College of Fisheries, Assam Agricultural University, Raha, Nagaon -782 103 (Assam), INDIA \\ ${ }^{2}$ Department of Business Administration, Tezpur University, Tezpur -784 028 (Assam), INDIA \\ *Corresponding author. E-mail: pcbhuyan19@gmail.com \\ Received: July 27, 2016; Revised received: January 13, 2017; Accepted: April 13, 2017
}

\begin{abstract}
The study was conducted in Nagaon district under central Brahmaputra valley zone of Assam to find out the perceptual constraints of the fish farmers in adoption of composite carp culture practice. A representative sample of 60 fish farmers of the district was selected using random sampling. The levels of agreement of respondents in relation to 32 identified constraints in adoption of composite fish culture were determined using 5 point Likert scale. The mean value of degree of responsiveness to constraints was analyzed to find out the perception of the farmers and found lack of fish feed at cheaper rate (3.45) as major constraint followed by high initial cost of digging of ponds (3.28). Seven factors of constraints have been identified through factor analysis such as extension support system constraints, knowledge constraints, financial constraints, distribution constraints, infrastructural constraints, agro-climatic constraints and situational constraints. With the constraints as perceived by the farmers, some relevant strategies have been suggested such as integrated effort to provide better quality fish seed at proper time at pond site of farmers through judicious carp breeding and hatchery management and proper distribution system; strengthening research extension linkage; organizing need based short and long-term training programme and on farm demonstration programme on various aspects of fish culture practices both for farmers and extension workers; establishment of 'One stop Aqua Shop'(OAS) as single outlet in strategic locations to make available all inputs required for fish culture; formation of fish producer's consortium to provide a dependable market support and a suitable delivery system for providing inputs to the fish farmers in time and better provision of institutional credit.
\end{abstract}

Keywords: Central Brahmaputra valley zone, Composite fish culture, Perceived constraints, Strategies

\section{INTRODUCTION}

Carps constitute the significant dominant group of fishes in the domestic market accounting for about 85 $\%$ of total inland freshwater aquaculture production of the country for which India is called as a "Carp country" ( DAHDF, 2016). The composite carp culture with three species of Indian major Carps (Catla, Rohu and Mrigal) and three of exotic carps (Silver carp, Grass carp and Common carp) developed during 70s have been widely adopted in India. This technology helped a great deal in increasing the fish yield from $600 \mathrm{~kg} / \mathrm{ha} /$ year under traditional practices to $5000 \mathrm{~kg} /$ ha/year depending upon the use of appropriate technology package (Kumar et al., 2009). Introduction of improved technology of fish farming and the efforts of Fish Farmers Development Agencies (FFDAs), the national average productivity of ponds and tanks under the programme had reached to $2900 \mathrm{~kg} / \mathrm{ha} /$ year (DAHDF, 2013). Many farmers and entrepreneurs in states like Andhra Pradesh, West Bengal, Punjab and Haryana have already achieved a production level of $6000-8000 \mathrm{~kg} / \mathrm{ha} /$ year under composite fish culture in ponds and tanks (Gopal et al., 2012). But, the present average fish production under semi-intensive composite fish culture in Assam is only $2200 \mathrm{~kg} / \mathrm{ha} /$ year.

Fishery sector is considered as an important economic activity in the socio-economic context in Assam. It is blessed with inland water bodies covering about 4.8 lakh ha in the form of rivers (2.05 lakh ha), beels (1.0 lakh ha), ponds and tanks (0.6 lakh ha), derelict water bodies (1.16 lakh ha), forest fisheries (0.05 lakh ha) etc. having a greater potentiality. But, the present fish production is only 0.282 million tonnes during 201415 , against an annual demand of 0.33 million tonnes which is calculated on the basis of minimum nutritional requirement of $11 \mathrm{~kg}$ per capita per annum as recommended by WHO and considering $95 \%$ of the state's population is fish eaters (Economic Survey, Assam- 2014-15).

In spite of having vast aquatic resources and location specific carp culture technologies, fishers have failed to achieve potential yield of fish from pond aquaculture in the state. The development of fisheries and aquaculture has been affected by a number of constraints in most of the developing countries. Identification of potential 
constraints is important for growth and development of fisheries sector. The constraints of production and marketing of fish had been studied by a number of researchers in different time and place (Sahoo et al. 2016; Abraham et al., 2010) but such studies are lacking in Assam. Problems experienced as impediments for development of fish culture in the state had been reviewed (Inaotombi and Mahanta, 2015; Bhuyan and Dutta, 2009; Kalita et al., 2001; Goswami and Sathiadhas, 2000) and found lack of quality fish seed, low temperature regime, shortage of fish feed were some of the important problems in the region. But, no adequate attention has been paid on systematic analysis of perceived constraints of farmers on adoption of fish culture technologies in Assam.

In view of above, the proposed investigation was made to find out perceived constraints of fish farmers of Nagaon district under the Central Brahmaputra valley zone of Assam in adoption of composite carp culture and to formulate strategies for improvement of composite fish culture based on the constraints analysis.

\section{MATERIALS AND METHODS}

The study was conducted in purposefully selected Nagaon district of Central Brahmaputra valley zone of Assam, which is one of the resourceful districts in terms of fisheries resource potential and fish production. A preliminary survey was conducted among 30 selected farmers following judgment sampling (Kothari, 2004) with an open ended questionnaire to identify their perceived constraints. A structured questionnaire was prepared after identifying probable constraints as perceived by the farmers and finally 32 constraints had been considered following a focus group discussion with fisheries officials of the Department of Fisheries, Govt. of Assam, scientists and academicians from Assam Agricultural University, Assam. Finally, a total of 60 farmers had been selected through random sampling from the list of fish farmers prepared in consultation with fisheries officials of Department of Fisheries, Nagaon district. For collection of responses from the respondents about constraints of composite fish culture and related information, the structured questionnaire designed based on the preliminary survey and focus group discussion was personally administered during the personal interview of survey method. The degree of responsiveness to different constraints in adoption of composite fish culture, as perceived by the farmers was collected by using 5 point Likert scale (1= Strongly Agree, 2= Agree, 3= Neither Agree nor Disagree, 4= Disagree, 5= Strongly Disagree), against 32 statements (variables) given in the questionnaire. The reliability test of the questionnaire containing questions in interval scale was carried out by applying Cronbach's Alpha method (Kothari, 2004). The Cronbach's Alpha value of 32 interval scaled measured statements relating to constraints of production and marketing of fish as perceived by the farmers was 0.884 indicating a good internal consistency of results. The relevant data collected were tabulated and analyzed using different statistical tools of SPSS package (version-16). Factor analysis was done using principal component analysis of SPSS to come up with a less number of constraints so that policies proposed may address the constraints. The Eigen values greater than 1 (Kaiser's criteria) were considered for retaining the variables (constraints). On the basis of factor loading greater than 0.5 , factors had been identified. Rotated component matrix has been observed to get the factors that can be named specifically and interpreted (Reddy and Ramesh, 2007; Lahiri and Samanta, 2010).

\section{RESULTS AND DISCUSSION}

General profile of the respondents: During the present study majority of respondents $(68.3 \%)$ were found in the age group between 21-40 years. Out of the total respondents, the majority belonged to General Caste $(61.7 \%)$, followed by OBC (30\%), SC (5\%) and ST (3.3\%). As regards educational status, $51.7 \%$ of respondents had qualification up to $12^{\text {th }}$ standards, 21.7 $\%$ were graduates, $20 \%$ below $10^{\text {th }}$ standard and only $6.7 \%$ primary school passed. $65 \%$ of respondents had nuclear type of family while $35 \%$ had joint family. Out of 60 respondents, 14 respondents $(23.3 \%)$ had taken fish culture as their primary occupation, while 46 respondents $(76.7 \%)$ had taken as secondary source of occupation. The average family size of the respondents was 6.12 . As regards operational land holding, about $38.3 \%$ of respondents had a land area of 1.0 ha, $35 \%$ respondents had 1.01 ha -2.0 ha and $26 \%$ respondents had 2.01 - 3.0 ha and the average land holding was $1.56 \mathrm{ha}$. The areas of individual pond were in between the ranges from 0.01 ha to 1.56 ha and the average was estimated at 0.37 ha. An average annual fish production was recorded from a minimum of $750 \mathrm{~kg} / \mathrm{ha} /$ year to the highest production $10,000 \mathrm{~kg} / \mathrm{ha} /$ year. But, $41.7 \%$ of the respondents had not taken any training on fish culture. The rest of farmers were undergoing only very short-term training programme. The farmers have adopted equally Multiple Stocking Multiple Harvesting (MSMH) and Single Stocking Single Harvesting (SSSH) type of semi-intensive composite fish culture system.

Constraints as perceived by farmers: The respondents were asked to express their level of agreement in relation to 32 identified perceived constraints in adoption of composite fish culture using 5 point Likert scale (Table 1). The mean value of Likert scale indicated that lack of fish feed at cheaper rate (3.45) was the major constraints followed by high initial cost of digging pond, high rent of water body, lack of expected result from fish culture, regular occurrence of flood, low water retention capacity of soil, acidic soil, lack of temperature for growth of fish, etc. in adoption of composite fish culture. Similar constraints in adoption 
Pradip C. Bhuyan et al. / J. Appl. \& Nat. Sci. 9 (2): 730 - 735 (2017)

Table 1. Perceived constraints of respondents in adoption of composite fish culture.

\begin{tabular}{|c|c|c|c|c|c|c|c|}
\hline S. No. & Constraints & SA & $\mathbf{A}$ & NAND & $\mathbf{D}$ & SD & Mean \\
\hline 1 & $\begin{array}{l}\text { Lack of chemicals/fertilizers at the time of } \\
\text { application }\end{array}$ & 58.3 & 35.0 & 1.7 & 5.0 & - & 1.53 \\
\hline 2 & Cost of medicine is high & 33.3 & 55.0 & 6.7 & 1.7 & 1.7 & 1.81 \\
\hline 3 & Lack of institutional credit & 25.0 & 61.7 & 3.3 & 8.3 & 1.7 & 2.00 \\
\hline 4 & Selling price of fish at farm site is low & 25.0 & 56.7 & 1.7 & 16.7 & - & 2.10 \\
\hline 5 & Cost of inorganic fertilizer is high & 6.7 & 66.7 & 6.7 & 20.0 & - & 2.40 \\
\hline 6 & Cost of fingerlings is high & 21.7 & 48.3 & 5.0 & 15.0 & - & 2.30 \\
\hline 7 & Rent of water body is more & 5.0 & 35.0 & 3.3 & 56.7 & - & 3.12 \\
\hline 8 & Lack of fish feeds at cheaper rate & - & 25.0 & 6.7 & 66.7 & 1.7 & 3.45 \\
\hline 9 & Lack of cold storage & 70.0 & 26.7 & 1.7 & 1.7 & - & 1.35 \\
\hline 10 & $\begin{array}{l}\text { Lack of irrigation facility to maintain water level in } \\
\text { pond }\end{array}$ & 30.0 & 63.3 & 3.3 & 3.3 & - & 1.88 \\
\hline 11 & $\begin{array}{l}\text { Lack of good quality fish seeds of required size and } \\
\text { number at the time of stock }\end{array}$ & 43.3 & 48.3 & 1.7 & 6.7 & - & 1.72 \\
\hline 12 & Renovation cost of old pond is high & 31.7 & 60.0 & 1.7 & 6.7 & - & 1.83 \\
\hline 13 & Lack of follow up action by extension workers & 46.7 & 41.7 & 1.7 & 10.0 & - & 1.75 \\
\hline 14 & Lack of market infrastructure & 38.3 & 46.7 & 3.3 & 11.7 & - & 1.88 \\
\hline 15 & Inadequate training programme on fish culture & 20.0 & 65.0 & - & 11.7 & - & 2.10 \\
\hline 16 & Poor extension support system & 25.0 & 58.3 & 3.3 & 13.3 & - & 2.05 \\
\hline 17 & Lack of follow up action by extension workers & 23.3 & 65.0 & - & 11.7 & - & 2.00 \\
\hline 18 & Inadequate visit of extension personnel to farm site & 23.3 & 65.0 & - & 11.7 & - & 2.00 \\
\hline 19 & Lack of expected result from fish culture & 1.7 & 41.7 & 3.3 & 51.7 & - & 3.10 \\
\hline 20 & Initial cost of digging of pond is high & 1.7 & 35.0 & 1.7 & 6.7 & - & 3.28 \\
\hline 21 & Lack of technological know how & 6.7 & 78.3 & 1.7 & 13.3 & - & 2.22 \\
\hline 22 & $\begin{array}{l}\text { Lack of knowledge about application of inputs (lime, } \\
\text { fertilizer, manures and chemicals at proper dosages } \\
\text { and methods) }\end{array}$ & 6.7 & 71.7 & - & 21.7 & - & 2.37 \\
\hline 23 & $\begin{array}{l}\text { Lack of knowledge of soil and water quality } \\
\text { management }\end{array}$ & 38.3 & 50.0 & 1.7 & 10.0 & - & 1.83 \\
\hline 24 & Lack of suitable temperature for growth of fish & 5.0 & 40.0 & 35.0 & 18.3 & 1.7 & 2.72 \\
\hline 25 & Soil is acidic & - & 50.0 & 25.0 & 25.0 & - & 2.75 \\
\hline 26 & Water retention capacity of soil is low & 3.3 & 48.3 & 46.7 & - & 1.7 & 2.95 \\
\hline 27 & Monsoon is Irregular & 10.0 & 73.3 & 1.7 & 13.3 & 1.7 & 2.23 \\
\hline 28 & Occurrence of disease & 16.7 & 76.7 & 1.7 & 3.3 & 1.7 & 1.97 \\
\hline 29 & Poisoning the water body & 10.0 & 56.7 & 10.0 & 21.7 & 1.7 & 2.48 \\
\hline 30 & Poaching of fish & 6.7 & 58.3 & 6.7 & 26.7 & 1.7 & 2.58 \\
\hline 31 & Occurrence of drought & 10.0 & 51.7 & 6.7 & 28.3 & 3.3 & 2.63 \\
\hline 32 & Occurrence of flood & 11.7 & 31.7 & $\therefore$ & 51.7 & 5.0 & 3.07 \\
\hline
\end{tabular}

(Note: $\mathrm{A}=$ Strongly Agree, $\mathrm{A}=$ Agree, $\mathrm{NAND}=$ Neither Agree Nor Disagree, $\mathrm{D}=$ Disagree, $\mathrm{SD}=\mathrm{Strongly}$ Disagree. All the figures given in the tables except mean are the percentage of responsiveness against the statement).

of scientific fish farming were reported by many researchers in different parts of India (Ananth et al., 2014; Mohanty et al., 2011; Abraham et al. 2010)

Factor analysis and formulation of strategies: Factor analysis was carried out to reduce the number of variables and found that among 32 variables few were more related to each other. To identify the respondent's perception towards different statements so as to group them into specific factors, factor analysis was done using principal component analysis of SPSS (Table 2).
The factor analysis revealed (Table 2) that 12 factors extracted together account for $77.69 \%$ of the total variance. The Eigen values greater than 1 (Kaiser's criteria) were considered for retaining the 12 variables. On the basis of factor loading greater than $0.5,12$ factors have emerged. Rotated component matrix has been observed (Lahiri and Samanta, 2010) to get the factors that can be named specifically and interpreted below:

Factor-1: It was combination of five original variables, which had factor loading greater than 0.5 (derived 
Pradip C. Bhuyan et al. / J. Appl. \& Nat. Sci. 9 (2): 730 - 735 (2017)

Table 2. Total Variance Explained (Extraction Method: Principal Component Analysis).

\begin{tabular}{|c|c|c|c|c|c|c|}
\hline \multirow[t]{2}{*}{ Component } & \multicolumn{3}{|c|}{ Initial eigen values } & \multicolumn{3}{|c|}{ Rotation sums of squared loadings } \\
\hline & Total & $\%$ of Variance & Cumulative \% & Total & $\%$ of Variance & Cumulative \% \\
\hline 1 & 5.013 & 15.665 & 15.665 & 3.305 & 10.327 & 10.327 \\
\hline 2 & 4.555 & 14.234 & 29.898 & 2.614 & 8.169 & 18.496 \\
\hline 3 & 2.219 & 6.934 & 36.833 & 2.373 & 7.417 & 25.913 \\
\hline 4 & 2.167 & 6.771 & 43.604 & 2.043 & 6.384 & 32.297 \\
\hline 5 & 1.799 & 5.622 & 49.226 & 1.985 & 6.205 & 38.502 \\
\hline 6 & 1.589 & 4.964 & 54.190 & 1.876 & 5.863 & 44.364 \\
\hline 7 & 1.392 & 4.350 & 58.540 & 1.868 & 5.836 & 50.200 \\
\hline 8 & 1.316 & 4.113 & 62.654 & 1.814 & 5.668 & 55.868 \\
\hline 9 & 1.253 & 3.916 & 66.569 & 1.785 & 5.580 & 61.448 \\
\hline 10 & 1.121 & 3.504 & 70.074 & 1.683 & 5.260 & 66.707 \\
\hline 11 & 1.109 & 3.465 & 73.539 & 1.600 & 5.000 & 71.707 \\
\hline 12 & 1.008 & 3.150 & 76.689 & 1.594 & 4.982 & 76.689 \\
\hline 13 & 0.870 & 2.719 & 79.408 & & & \\
\hline 14 & 0.808 & 2.526 & 81.934 & & & \\
\hline 15 & 0.719 & 2.247 & 84.181 & & & \\
\hline 16 & 0.644 & 2.014 & 86.195 & & & \\
\hline 17 & 0.625 & 1.952 & 88.147 & & & \\
\hline 18 & 0.519 & 1.623 & 89.770 & & & \\
\hline 19 & 0.469 & 1.465 & 91.235 & & & \\
\hline 20 & 0.418 & 1.307 & 92.542 & & & \\
\hline 21 & 0.399 & 1.246 & 93.788 & & & \\
\hline 22 & 0.340 & 1.062 & 94.850 & & & \\
\hline 23 & 0.294 & 0.918 & 95.768 & & & \\
\hline 24 & 0.283 & 0.885 & 96.653 & & & \\
\hline 25 & 0.242 & 0.757 & 97.410 & & & \\
\hline 26 & 0.224 & 0.701 & 98.111 & & & \\
\hline 27 & 0.157 & 0.490 & 98.601 & & & \\
\hline 28 & 0.136 & 0.424 & 99.025 & & & \\
\hline 29 & 0.124 & 0.387 & 99.412 & & & \\
\hline 30 & 0.094 & 0.294 & 99.706 & & & \\
\hline 31 & 0.058 & 0.182 & 99.888 & & & \\
\hline 32 & 0.036 & 0.112 & 100.000 & & & \\
\hline
\end{tabular}

from rotated component matrix) - lack of good quality fish seeds of required size and number at the time of stock (0.537), inadequate training programme on fish culture (0.738), poor extension support system (0.704), inadequate visit of extension personnel to farm site (0.644), and lack of follow up action by extension worker (0.502). This factor was named as 'extension support system constraints'. Pandey et al., (2014) also mentioned the poor extension support system as a constraint in transfer of aquaculture technologies in Manipur.

Strategies: The government should make an attempt to provide quality fish seed at pond site of farmers through judicious carp breeding and hatchery management, and proper distribution system. Centralized production of seed in hatcheries and rearing centers can be a major service to small and marginal farmers of the rural areas. The poor quality fish seed may be due to poor brood-stock management and inbreeding depression. To overcome this situation Assam Fish Seed Act, 2005 which was amended in 2010 by the Department of Fisheries, Govt. of Assam should be strictly followed. Need based training and demonstration programme on composite fish culture technology should be imparted to increase the skill of the farmers and follow up action by extension workers could be improved through strengthening the extension machineries. The technical competence and personal quality of extension personnel should be improved through skill development programmes. Necessary facilities for effective work in remote areas should be provided to the extension workers. Suitable transportation, audio-visual aids and 
financial provision for demonstration purpose are most essential.

Factor-2: It is a combination of three variables i.e. lack of knowledge about application of inputs (0.835), lack of technological know-how (0.618) and lack of knowledge of soil and water quality management (0.543). It is named as 'knowledge constraints'. Baruah et al. (2013) reported the importance of training need for fish grower of Assam to aware about the technological know-how to increase fish production.

Strategies: Proper information about application of inputs at proper dose and methods of application should be given to the farmers through organizing more short and long-term training programme and on farm demonstration programmes. The provision for testing soil and water quality parameter should be made available in the rural area.

Factor-3: It is the combination of six variables i.e. lack of institutional credit (0.780), lack of fish feed at cheaper rate (0.607), cost of medicine is high (0.601), cost of fingerlings is high (0.686), high initial cost of digging pond (0.508) and high cost of inorganic fertilizer (0.648). It is named as 'financial constraints'. Similar constraints were reported on the perceived problems of few communities of Andhra Pradesh in adopting composite fish culture by Mandal et al. (2011).

Strategies: There should be good provision for channelizing institutional credit to the farmers. It is suggested that institutional credit should be made available at lower rate of interest and its procedure should be simple. The banking sector should be invited to offer a single window loan provision in the form of loan mela where the less educated farmers can also be assisted in availing a loan. Researchers should come forward to formulate low cost fish feed using locally available ingredients. The high cost of fingerlings and excavation of ponds can be reduced through adoption of community based co-management approach.

Factor-4: It is a combination of three variables i.e. selling price at farm front is less $(0.556)$, lack of chemical fertilizer at the time of application (0.544) and lack of proper distribution channel (0.833). It is named as 'distribution constraints'.

Strategies: Introducing suitable fish delivery system can help the farmers to get remunerative price of fish at farm site. Fish producer's consortium should be formed at the rural areas which will provide a dependable market support and will provide a suitable delivery system for providing inputs to the fish farmers in time. Such concept not only provides a market mechanism but will be able to generate employment opportunities in rural areas. Establishment of one stop aqua shop (OAS) as single outlet in strategic locations to make available all inputs required for fish culture such as fish seed, fish feed, fertilizer, chemicals etc. should be encouraged.

Factor-5: It includes three variables i.e. lack of cold storage $(0.584)$, lack of market infrastructure $(0.513)$ and lack of irrigation facility (0.740). It is named as 'infrastructural constraints'. Das and Goswami (2002) also mentioned the lack of efficient marketing structure as a major constraint perceived by the fish farmers of Nagaon and Morigaon districts of Assam.

Strategies: Proper infrastructure related to storage and transportation in refrigerated condition should be provided. It will help to maintain the quality of fish and thereby farmers get remunerative price. The provision of cold storage should be encouraged to keep the seasonal produce to meet the off-season demand. Providing good irrigation facility at farm site will help to maintain the optimum water depth for fish culture and to exchange water when required.

Factor-6: It is the combination of three variables i.e. lack of suitable temperature throughout the year for growth of fish (0.782), soil is acidic (0.858) and monsoon is irregular (0.533). It is named as 'agro-climatic'.

Strategies: Lack of suitable temperature throughout the year is a constraint which retards the growth of carps. In this situation, farmers may take the advantage of the period when the suitable temperature $\left(26{ }^{0} \mathrm{C}-32\right.$ $\left.{ }^{0} \mathrm{C}\right)$ exists i.e., from March to September of the year (Baruah et al., 2013). They should stock the pond with carried over seed on the onset of pre monsoon that is in the month of March-April so as to provide optimum temperature for growth for long period of time. The acidic soil is not suitable for growth of fish for which farmers are suggested to apply proper dose of lime after testing the $\mathrm{pH}$ value of soil and water (Baruah et al., 2013). The farmers should try to adjust the work calendar of composite fish culture or induced breeding programme with the changing monsoon.

Factor-7: It includes four variables i.e. regular occurrence of flood (0.744), occurrence of disease (0.541), poaching of fish $(0.861)$ and poisoning the water body (0.574). It is named as 'situational constraints'. Strategies: More emphasis should be given on proper adoption of package of practice of short duration composite fish culture technology suitable for flood prone area. Establishment of Fishery Clinic with the facilities of soil and water testing, disease diagnosis and fish medicines at panchayat block level can help the farmers to overcome the problems of commonly occurred fish diseases in the state like EUS, Argulas, Dropsy etc..

Poaching and poisoning of fish is a social evil which is perceived as constraints of fish culture. This problem can be solved by educating the people through awareness camp and trying to motivate them for adoption of scientific fish culture, which can give them due social status. It is suggested for using of substrates in pond for periphyton growth that in turn work as hurdle to poach inside ponds. Social fencing through community participation will reduce the social constraints. Providing fishery insurance coverage can help mitigating the 
problem of poaching and poisoning.

Since, remaining five factors consisted of only one variable (constraint) each having factor loading 0.5 , these constraints had not been considered for strategies formulation.

\section{Conclusion}

The seven factors identified through factor analysis were extension support system constraints, knowledge constraints, financial constraints, distribution constraints, infrastructural constraints, agro-climatic constraints and situational constraints. These provide an insight in to the perceived constraints of fish farmers towards adoption of composite fish culture. The relevant strategies that have been formulated may be implemented for enhancing fish production through better adoption of composite fish culture. The result of the present study will help all stakeholders (famers, researchers, extension personels, financial institutions, policy makers etc.) of the fisheries development process in the state to streamline their thoughts and action to overcome the percievd constraints of composite fish culture. As a policy option, it is suggested that fish production can be enhanced through successful implementation of these strategies for which developmental projects, programmes and budgets have to be framed, implemented, monitored and managed scientifically.

\section{ACKNOWLEDGEMENTS}

Authors gratefully acknowledge the fish farmers of Nagaon district of Assam, India for their unconditional help during collection of the information's through group discussions and survey.

\section{REFERENCES}

Abraham, T. J., Sil, S. K. and Vineetha, P. (2010). A comparative study of the aquaculture practices adopted by fish farmers in Andhra Pradesh and West Bengal. Indian J. Fish., 57(3): 41-48

Ananth, P. N., Sahoo, P. R., Dash, A. K., Pati, B. K., Jayasankar, P. and Singh, S. R. K. (2014). A Study on Community Based Aquaculture Promoted by KVKKhordha, Odisha, India. Current World Environment, 9 (3):947-951

Baruah, U. K., Barman, J. Choudhury, H. and Bordoloi, P. (2013) Training needs of the freshwater fish growers in Assam, India. African J. Fish. Sci., 1(2) 5-10

Bhuyan, P. C. and Dutta, O. K. (2009). Strategic Management for enhancing fish production in Assam, In: Fish and Fisheries in North East India-Recent and Rebuilding. Bhuyan, R. N., Ghosh, D. and Sharma, D. (Ed.), Geophil Publising House, Guwahati, Shillong. 164-175
DAHDF, (2013). Annual Report 2011-12, Department of Animal Husbandry, Dairying and Fisheries, Government of India, New Delhi.

DAHDF, (2016). Annual Report 2015-16, Department of Animal Husbandry, Dairying and Fisheries, Government of India, New Delhi.

Das, S. K. and Goswami, U. C. (2002). Current status of culture fisheries in the Nagaon and Morigaon Districts of Assam. Applied Fish. Aqua., 11(2) 33-36

Economic Survey, Assam (2014-15). Directorate of Economics and Statistics. Govt. of Assam.

Gopal, T. K. S., Mohan, C. O., Nenan, G. and Ravishankar, C. N. (2012). Potential and future prospects for the processing and export of major carps. Fishing Chimes., 32 (1) $60-65$

Goswami, M. and Sathiadhas, R. (2000). Fish farming through community participation in Assam. Naga, The ICLARM Quarterly, 23(3): 29-32

Inaotombi, S. and Mahanta, P. C. (2015). Problems and prospects of fisheries development in North Eastern India, Asian .J. Multidisciplinary Studies, 3(10): 22-24

Kalita, K., Bhagabati, S. K. and Dutta, O. K. (2001). Problems and prospects of Fisheries in Assam. Fishing Chimes, 21 (3): 9-11

Kothari, C. R. (2004). Research Methodology- Methods and Techniques, $2^{\text {nd }}$ Ed. New Delhi: New Age International Pvt. Ltd.

Kumar, D., Munilkumar, S. and Rani, B. (2009). Concept of best management practices for freshwater aquaculture in India. In: Aquaculture Management, Goswami, U.C. and Kumar, D. (Ed.), Narendra Publishing House, Delhi, India. 1-6

Lahiri, I. and Samanta, P. K. (2010). Factors Influencing Purchase of Apparels from Organised Retail Outlets. The IUP J. Marketing Management, 9(1-2):73-84

Mandal, S. C., Burman, D. and Das, P. (2011). Modern approach of composite fish culture - the examples of Andhra Pradesh (India) to emulate. World Aquaculture, 44-46

Mohanty, R., Mishra, K. A., Ghosh, S. and Patil, D. U. (2011). Constraint analysis and Performance Evaluation of Participatory Agri-aquaculture in Watersheds. Indian J. Fish., 58(4): 139-145

Pandey, D. K., De, H. K., Hijam, B. (2014). Fish Farmers' perceived constraints in transfer of aquaculture technology in Bishnupur district of Manipur, India. Int. J. Fish. Aqua. Studies, 2(1):01-04

Reddy, D. Y. and Ramesh, A. (2007). "A study on attitudes towards packaged fruit drinks using exploratory factor analysis. The IUP J. Marketing Management, 2(4):1723

Sahoo, P. R., Ananth, P. N., Dash, A. K, Pati, B. K., Barik, N. K. and Jayasankar, P. (2016). Institution based intervention on promoting composite fish culture in rural Odisha: A case of KVK-Khordha. Int. J. Fish. Aqua Studies, 4(4): 190-195 